point of view such as is so characteristic of most popular science writing, but instead a clear presentation of current scientific opinion as it has been incorporated into Professor Ames's own thinking.

The first lecture lays the foundation for the remainder by an admirable and a very discerning historical discussion of the introduction into physics of the concepts of mass, force, the ether, energy, molecules, atoms and corpuscles. Concerning this chapter I would make but two comments: It is a pity that all other writers have not shown as much discrimination in the use of the terms corpuscle and electron. The latter term was introduced into physics in 1891 by G. Johnstone Storey to denote the "natural unit of electricity" altogether without reference to the inertia which might be associated with it and it is surely desirable to-day to have some word to denote this idea. Electron is obviously the logical word for the purpose. A negative electron when associated with the smallest inertia which is ever found to accompany an electron, namely, 1/1830th that of the hydrogen atom, was called by Thomson a corpuscle, and Professor Ames wisely follows this usage. I can not myself be quite so enthusiastic about the statement that "a system has potential energy if it is in its natural condition" or indeed about the way in which the idea of potential energy is used throughout the first and second chapters, especially throughout the second, which deals primarily with the subject of electromagnetic mass. There is a sentence in one of the later lectures which reads as follows: "There is no word, I think, in our language which is so much used to conceal ignorance as ' heat,' and no word about which there is so much confusion of ideas as 'temperature.'" I should like to insert in each clause "except the word energy." The third lecture treats together the newest and the oldest of the departments of physics, namely, radioactivity and gravitation, the former quite briefly (excellent judgment again), the latter quite at length but with a freshness and power which is born only of a very thorough and profound knowledge of original sources.
The fourth, fifth and sixth lectures are the finest and most stimulating of the course. They deal respectively with (4) the problems of radiation, (5) the electron theory of conduction, thermoionies and magnetism, (6) models of atoms and fundamental concepts of nature. These chapters represent I think the best general discussion which has appeared in English of the big problems which the researches of the past two decades have presented to modern physics.

\section{R. A. Millikan}

RYERSON LABORATORY, UNIVERSITY OF ChICAgo

The Chemistry of Cattle Feeding and Dairying. By J. Allan Murray. London, Longmans, Green and Co. 1914. Octavo. Pp. 343.

This book discusses briefly (1) the constituents of plants and animals, (2) the nutritive requirements of animals, (3) feeding stuffs and (4) dairy chemistry. The treatment is, in the main, elementary in character. The distinctive feature is an attempt to break away from the Wolff and the Kellner feeding standards, especially in recognition of the fact that the nutritive requirements of animals do not vary directly as the live weight. The point of view is rational, and the tentative formulæ suggested for the separate computation of food requirements for maintenance, labor, milk production, growth and fattening constitute a notable step in a direction in which progress is much to be desired. The discussion of the chemistry of the subject is generally satisfactory.

The author's statements regarding the functions of the mineral elements, and regarding other matters of physiology and histology, are frequently lacking in discrimination. We quote a few such passages:

Page 8: "The ingredients of the ash are not ' mineral.' They are just as much organic matter as the fats or proteins."

Page 9: "It is probable, however, that the chlorides naturally present in the food of herbivora are sufficient to provide all the hydrochloric acid required." 
Page 10: "Potassium compounds appear to be of minor importance in the economy of animals. They occur in the blood of all herbivora as a necessary consequence of their presence in the food."

"Potassium compounds . . form nearly one quarter of the ash of milk. . . A farmer producing milk, therefore, will find it profitable to use potash manures unless his soil is naturally well stocked with that ingredient. Practically the whole of the potash in the food, except what is exported in the milk, is returned to the land in the droppings of the animals."

Page 13: Referring to the ingredients of the ash the author says: "From the point of view of the practical cattle feeder they are all unimportant, inasmuch as they are always present in the natural food of the animals."

Page 15: "Carbohydrates are produced by animals only in insignificant quantities."

Page 46: "Fats do not form part of the tissues of plants as they do in animals."

Page 93: "The composition and properties of lactochrome . . . are quite unknown."

Page 99: "The collagen (of bones) acts as a kind of cement and holds the particles of mineral matter together."

Page 104: "No means is known by which this difficulty (the presence of metabolic nitrogen in the feces) can be overcome; but the amount of such ingredients is probably small and approximately constant. In practise it is ignored."

Page 109: In discussing the absorption of nutrients and their passage into the blood and to the heart, the liver is not mentioned.

Page 132: "This amount (the maintenance requirement of digestible protein) may be estimated, as previously shown, from the amount of nitrogen in the urine which contains all of the nitrogenous products of metabolism."

Much of the matter relative to foods is of local significance and not applicable to the United States, thus (page 255), referring to the storage of ensilage in a silo, "the expense is greater than that involved in the waste of fodder when the silage is made in a stack."
"When the expense of a built silo or the alternative loss due to charring at the outside of a stack is added to the losses due to fermentation, it is obvious that silage making is not a profitable method of preserving fodder; and is now rarely practised in this country."

E. B. Forbes

\section{Agricultural Experiment Station, WOOSTER, O. \\ SCIENTIFIC JOURNALS AND ARTICLES}

The July number (Vol. 15, No. 3) of the Transactions of the American Mathematical Society contains the following papers:

H. F. Blichfeldt: "A new principle in the geometry of numbers, with some applications."

F. R. Sharpe and C. F. Craig: "An application of Severi's theory of a basis to the Kummer and Weddle surfaces."

L. P. Eisenhart: "Transformations of surfaces of Voss."

F. R. Sharpe and Virgil Snyder: "Birational transformations of certain quartic surfaces."

G. M. Green: "One-parameter families of curves in the plane."

G. A. Bliss and A. L. Underhill: "The minimum of a definite integral for unilateral variations in space."

L. D. Cummings: "On a method of comparison for triple-systems."

W. R. Longley: "An existence theorem for a certain differential equation of the $n$th order."

The June number (Vol. 20, No. 9) of the Bulletin of the American Mathematical Society contains: Report of the spring meeting of the society at Chicago, by H. E. Slaught; "On ovals," by Tsuruichi Hayashi; "On the class of doubly transitive groups," by W. A. Manning; Review of Christoffel's Gesammelte mathematische Abhandlungen, by L. P. Eisenhart; Review of Vivanti's Esercizi di Analisi infinitesimale and Dingeldey's Sammlung von Aufgaben zur Anwendung der Differentialund Integralrechnung, by R. C. Archibald; "Shorter Notices;" Heiberg's Archimedis Opera Omnia, volume II., Heath-Kliem's Archimedes' Werke, and Mænnchen's Geheim- 